\title{
INSPEÇÃO TERMOGRÁFICA NO ANTIGO PRÉDIO DCTEF-USFJ
}

\author{
Marcel Henrique Lopes ${ }^{(1)}$ marcel.henrike@ hotmail.com, Sávio Brenner ${ }^{(1)}$ saviobrenner97@gmail.com, \\ Jorge Nei Brito ${ }^{(2)}$ brito@ufsj.edu.br \\ (1) Univ. Federal de São João Del Rei (UFSJ) - Grupo de Estudos e Pesquisas do Laboratório de Sistemas Dinâmicos (Gep_LASID) \\ (2) Universidade Federal de São João Del Rei (UFSJ) - Departamento de Engenharia Mecânica (DEMEC)
}

RESUMO: A termografia é uma técnica de manutenção preditiva não destrutiva, onde é possível acompanhar a temperatura e os termogramas da região de estudo desejada. A análise da variação de temperatura é muito importante para compreensão e detecção de falhas tanto elétricas como mecânicas. Essa técnica também é empregada na construção civil, na detecção de vazamentos, correntes de ar e fissuras. Foi realizada uma inspeção termográfica no antigo prédio DCTEF-UFSJ, com o auxílio de uma câmera termográfica (modelo FLIR T200) e um termo higrômetro digital, baseada nos estudos feitos anteriormente, existem parâmetros para a configuração da câmera, como a temperatura ambiente, temperatura da parede e a humidade relativa do ar, obtidas pelo higrômetro digital além da emissividade do concreto $\varepsilon=0,97$, sendo esse último parâmetro mantido constante devido a todas as paredes analisadas serem feitas desse material. Essa análise foi realizada com o intuito de identificar possíveis infiltrações e acúmulos de umidade para verificar se as condições do prédio estão adequadas para a mudança da DICON e o armazenamento de arquivos. A partir das imagens obtidas pela inspeção, observou-se que a frente do prédio, que possui maior insolação e ventilação não apresentou grandes problemas de infiltração, em contrapartida as salas no fundo do prédio possuem um maior foco de umidade e infiltração, além de um forte cheiro de mofo.

PALAVRAS-CHAVE: Manutenção preditiva, Termografia Infravermelha, Construção Civil.

\section{INTRODUÇÃO}

A Manutenção Preditiva é definida como manutenção que permite garantir uma qualidade de serviço desejada, com base na aplicação de técnicas de análise, utilizando-se meios de supervisão ou de amostragem (Oliveira, 2012).

Há algum tempo a utilização de ensaios não destrutivos tem se mostrado importante ferramenta para o controle do desempenho dos materiais em serviço. Esses ensaios são definidos como sendo aqueles que não prejudicam nem causam danos ao uso futuro do elemento ensaiado, ou seja, não provocam perda na capacidade resistente do elemento (Pedra, 2011).

Dentre as técnicas de análise não destrutiva, a Termografia Infravermelha tem sido utilizada para aplicações em diversos campos de atuação.

A Termografia Infravermelha é a Manutenção Preditiva que permite o acompanhamento de temperatura e a formação de imagens térmicas, denominada de termogramas. A temperatura é um dos parâmetros de mais fácil compreensão, e o acompanhamento de sua variação é muito importante tanto para equipamentos elétricos como mecânicos, pois permite constatar uma alteração na condição de equipamentos, componentes e do próprio processo como um todo (Souza, 2011).

Na construção civil, esta técnica tem sido empregada para a detecção de vazamentos, inspeção térmica de entorno de novas obras e testes térmicos para conservação de patrimônio histórico. Em 

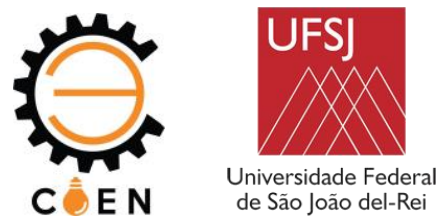

síntese, as técnicas de termografia permitem a visualização da edificação, possibilitando a identificação da presença de elementos e anomalias ocultos (Cortizo, 2007).

Segundo Cortizo (2007), para a identificação de estruturas e anomalias de uma edificação pode-se utilizar o mecanismo de radiação empregando a termografia digital (medição de temperatura sem contato) ou de condução, por meio de termopares (medição de temperatura com contato). A mensuração do mecanismo de condução ocorre pela determinação dos gradientes de temperatura do corpo. Existem inúmeros métodos e técnicas de determinação da distribuição de temperatura, com e sem contato com a superfície.

A Termografia Infravermelha pode ser apresentada como sendo a técnica de um método não destrutivo sem contato de identificação visual do gradiente de temperatura superficial de um corpo em condições ambientais.

A Termografia Infravermelha, com base na análise do campo de temperatura, é capaz de identificar anomalias internas porque o processo de difusão térmica, afetado pela presença de falhas, gera uma alteração do campo de temperatura superficial da estrutura em comparação ao campo de temperatura gerado por uma estrutura íntegra.

Embora possam ser detectadas anomalias internas, segundo Lá Fé (2017), a Termografia Infravermelha é considerada uma técnica superficial, já que as anomalias que podem ser identificadas são as que ficam perto da superfície, conforme detalhado a seguir.

- Deslocamentos: Os descolamentos de revestimentos são algumas das patologias estudadas com a termografia infravermelha. A espessura relativamente pequena da maioria dos materiais de revestimento e a presença de ar entre as camadas deles como resultado da perda de aderência com o substrato são dois dos fatos que justificam o estudo deste fenômeno com a termografia de infravermelho.

- Fissuras: A termografia infravermelha tem sido utilizada na avaliação de fissuras, principalmente, fissuras superficiais em revestimentos externos em argamassa ou elementos de concreto. A camada de ar dentro da fissura e sua geometria estreita são dois dos fatos que facilitam o estudo desta patologia.

Quando o calor penetra ou sai da fissura, parte da radiação é refletida nas paredes e parte é absorvida, por tais motivos, esta região não fica aquecida da mesma forma que a superfície totalmente exposta, o que gera diferenças que podem ser detectadas na inspeção termográfica.

- Umidades: A umidade é uma das patologias das construções que mais tem sido estudada com o uso da termografia de infravermelho. A umidade em materiais porosos (como os materiais de construção) se espalha nos poros até seu enchimento. A água modifica radicalmente a densidade, o calor específico e a condutividade térmica.

Através da Termografia Infravermelha também é possível identificar locais de perdas de calor ou de frio, identificar o traçado de tubagens, localizar elementos estruturais embebidos em paredes, ou detectar a existência de colónias de insetos no interior de elementos de madeira da construção, sendo uma técnica de análise económica, de tempo real (Silva, 2016).

\section{CONFORTO TÉRMICO}

De acordo com a norma ISO 7730, "conforto térmico é o estado de alma que expressa satisfação com o ambiente térmico". O termo "conforto térmico" é de fato bem subjetivo, em outras palavras, não podemos definir tal conforto apenas como uma determinada temperatura. Também 



devem ser consideradas a velocidade do vento, a humidade do ar, a saúde mental daqueles que utilizam o espaço e suas vestimentas, além do tipo de atividade que eles irão realizar (Gallo e Ribeiro, 2007)

Pessoas que realizam trabalho braçal tendem a se sentirem mais confortáveis com temperaturas mais baixas, em contrapartida atividades que exigem menos esforço físico, faz com que as pessoas optem por temperaturas mais amenas como $23^{\circ} \mathrm{C}$. O mesmo pode ser dito sobre suas vestimentas, tendo em vista que pessoas com roupas mais leves ficarão mais confortáveis com temperaturas mais altas do que alguém de terno e gravata.

A geometria da sala também é de extrema importância quando o assunto é o conforto térmico. $\mathrm{O}$ ar condicionado pode ser um incomodo devido suas correntes de ar, já a região perto de janelas também pode ser um problema devido a incidência solar.

A umidade relativa do ar e a temperatura são fatores cruciais para a preservação de documentos e livros. É recomendado locais com humidade relativa do ar entre $50 \%$ à $55 \%$ e temperatura em $20^{\circ} \mathrm{C}$. A ventilação do ambiente e a insolação são fundamentais para a obtenção das condições ideais. Caso exista a possiblidade da climatização do espaço, ventiladores, ventilação cruzada, e canais de ventilação são possibilidades indicadas a fim de se otimizar a conservação do acervo. (Portal do governo, 2016)

\section{OBJETIVOS}

O objetivo deste trabalho é identificar possíveis infiltrações e ou umidade no antigo prédio do Departamento de Engenharia Mecânica (DEMEC) e Departamento Ciências Térmicas e dos Fluidos (DCTEF), Figura 1, visando o uso destas instalações pela Divisão de Acompanhamento e Controle Acadêmico (DICON), tanto no que se refere a Equipe Técnica quanto os arquivos ativos e inativos.

Destaca-se que esse espaço físico tem de ter as condições ideais no que se refere às condições térmicas ideais, ou seja, sem infiltrações ou umidades que possam colocar em risco a saúde dos colaboradores e a integridade dos documentos.

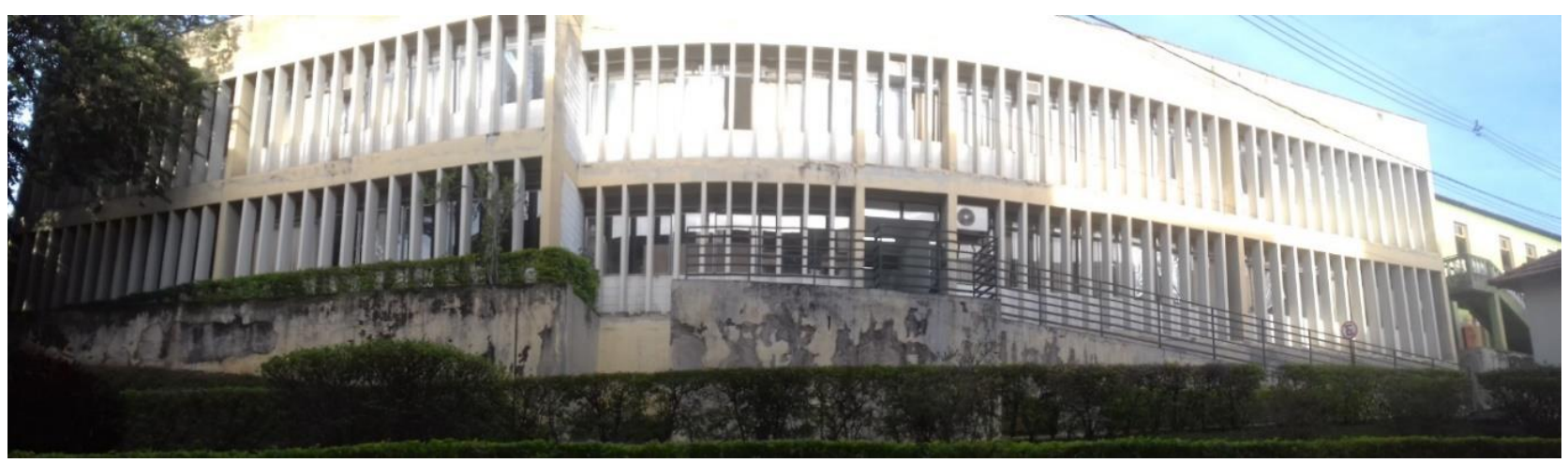

Figura 1. Antigo prédio do DEMEC e DCTEF. Fonte: Autor (2019).

Na Figura 2 tem-se a planta baixa do antigo prédio do DEMEC e DCTEF. Na Figura 3 temse o termograma do antigo prédio do DEMEC e DCTEF. 

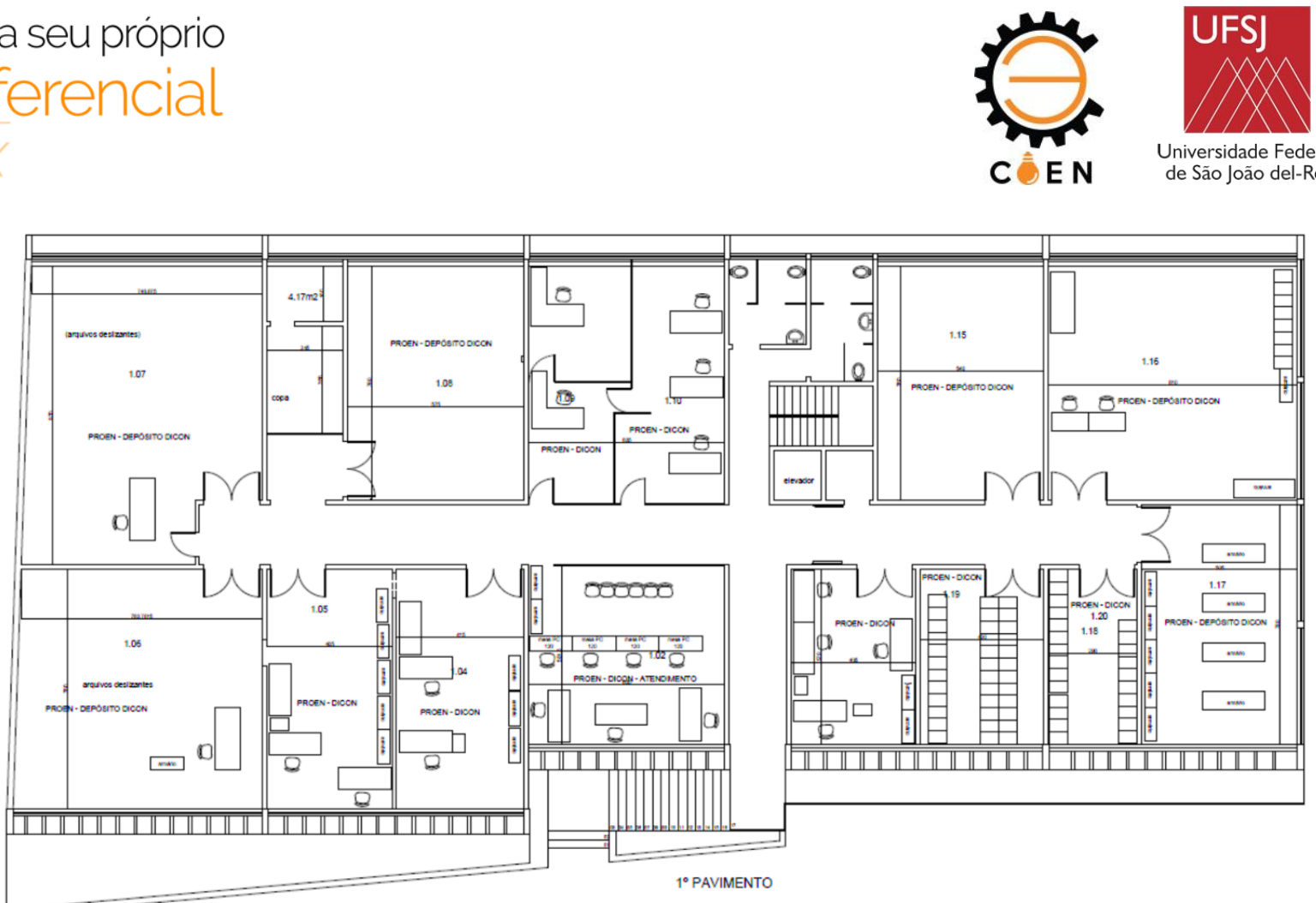

Figura 2. Planta baixa antigo prédio DEMEC e DCTEF $\mid 1^{0}$ Pavimento. Fonte: Autor (2019).

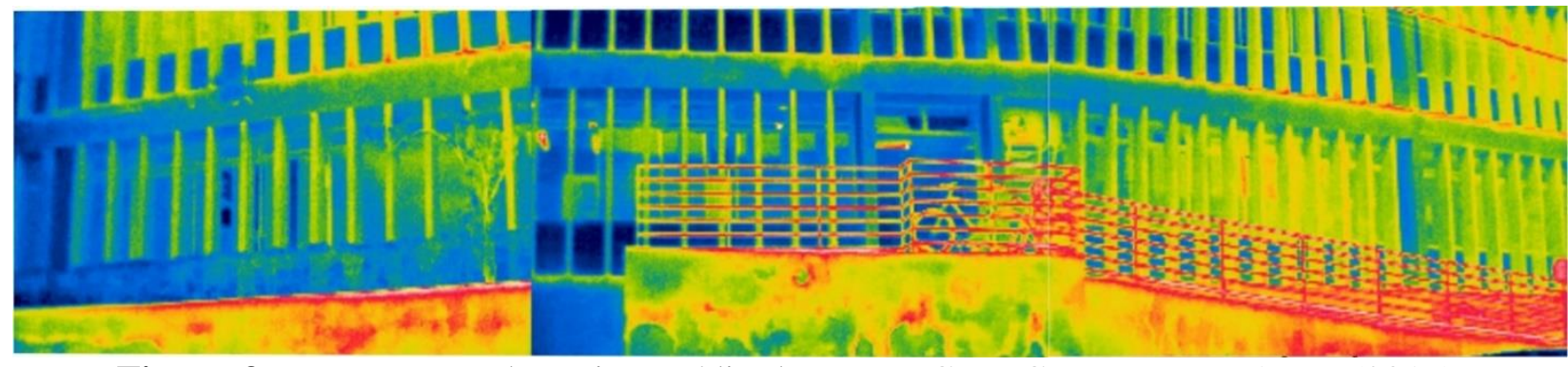

Figura 3. Termograma do antigo prédio do DEMEC e DCTEF. Fonte: Autor (2019).

\section{BREVE FUNDAMENTAÇÃO TEÓRICA}

As ondas, em função de sua origem, podem ser mecânicas ou eletromagnéticas. As ondas eletromagnéticas, compostas de campos elétricos e magnéticos, podem ser geradas por fenômenos naturais, como o Sol, ou criadas pelo homem. Os exemplos de ondas eletromagnéticas vão desde as micro-ondas até a radiação gama. A radiação infravermelha faz parte do espectro eletromagnético e se comporta de modo similar à luz visível, atravessando o espaço na velocidade da luz. Pode ser refletida, absorvida, emitida e transmitida através de um corpo sólido (Incropera e Dewitt, 2008).

De acordo com Incropera e Dewitt (2008), sempre que existir uma diferença de temperatura em um meio ou entre meios diferentes, ocorre, necessariamente transferência de calor. Os mecanismos de transferência de calor são: radiação, condução e convecção, e na maioria das situações reais, ela é consequência da combinação delas.

A seguir apresenta-se uma síntese sobre "Condução", "Convecção" e "Radiação".

\subsection{Condução}


O processo de transmissão de calor por condução ocorre quando a energia passa de molécula para molécula sem movimento de um meio, ou seja, resulta da capacidade térmica do material transmitir energia pelo contato direto, por meio de movimentos e choques entre átomos e/ou moléculas vizinhas.

$\mathrm{Na}$ Equação 1 tem-se, de acordo com a segunda a Lei de Fourier, o calor transferido por condução $\left(\boldsymbol{Q}_{\text {cond }}\right)$ para um regime estacionário de condução, onde $\mathbf{L}$ é o comprimento, $\mathbf{k}$ é a condutibilidade térmica do material, $\Delta \mathbf{T}$ é a diferença de temperatura entre as suas extremidades e $\mathbf{A}$ a área da seção transversal.

$$
Q_{\text {cond }}=\frac{k A \Delta T}{L}
$$

A condutibilidade térmica quantifica a capacidade dos materiais de conduzirem calor, podendo definir-se como a quantidade de calor que atravessa por unidade de tempo um elemento dum material homogéneo. Assim sendo, materiais com alta condutibilidade térmica conduzem melhor o calor que aqueles com baixa condutibilidade térmica.

\subsection{Convecção}

O termo convecção é usado para descrever a transferência de energia entre uma superfície e um fluido em movimento sobre esta superfície. A convecção inclui transferência de energia pelo movimento global do fluido - advecção - e pelo movimento aleatório das moléculas do fluido - difusão (Incropera; Dewitt, 2008).

O calor transferido por convecção $\left(Q_{c o n v}\right)$ é calculado através da Equação 2 , onde $\boldsymbol{h}$ é o coeficiente de transferência de calor por convecção.

$$
Q_{\text {conv }}=h A\left(T_{w}-T_{\infty}\right)
$$

O mecanismo depende basicamente de dois processos: troca de calor e transporte de massa. A convecção ocorre como consequência de diferenças na densidade da substância, causada pela variação de temperatura no meio da própria substância, geralmente há uma superfície aquecida que vai passar calor a essa substância que vai sofrer convecção.

A convecção natural se dá pela imersão de um corpo com maior ou menor temperatura em um fluido ou pelo fornecimento de calor a um recipiente que possui um fluido (por exemplo, chama em uma panela). O calor é transmitido na superfície do corpo para o fluido por condução e, em consequência da diferença de temperaturas, o calor flui entre as camadas vizinhas do fluido, causando uma corrente de convecção.

\subsection{Radiação}

A transferência de calor por meio da radiação $\left(Q_{r a d}\right)$, Equação 3, ocorre quando um corpo cuja temperatura seja superior a zero absoluto, emite energia sob a forma de radiação, onde $\sigma$ é a constante de Stefan-Boltzmann; $\boldsymbol{F}_{\mathbf{1 2}}$ é o fator de forma e $\varepsilon$ é a emissividade. Entre dois corpos, ocorrem trocas 
de energia por radiação, que, entre outros fatores, dependem das suas capacidades de emissividade e absorção dessa mesma energia.

$$
Q_{\text {rad }}=\sigma F_{12} A\left(T_{\text {corpo }}{ }^{4}-T_{a m b}{ }^{4}\right)
$$

A radiação térmica, é uma forma de transferência de calor não necessita de um meio para se propagar e ocorre por meio de ondas eletromagnéticas. A energia térmica radiante é emitida na gama de comprimentos de onda entre $\mathbf{0 , 1}$ a $100 \mu \mathrm{m}$ do espectro eletromagnético. Como essas ondas se podem propagar no vácuo, não é necessário que haja contato entre os corpos ou qualquer meio material entre eles para haver transferência de calor.

A radiação emitida pela superfície de um material tem sua origem na energia térmica da matéria limitada pela superfície e a taxa na qual a energia é liberada por unidade de área é denominada poder emissivo da superfície. A relação existente entre a energia emitida por um corpo real, em relação a um corpo negro, sob a mesma temperatura é conhecida como emissividade (\&). A emissividade determina a maior ou menor quantidade de energia que um corpo emite em um dado comprimento de onda (Incropera; Dewitt, 2008).

De forma simplificada, pode-se dizer que emissividade é a capacidade que um corpo tem de emitir radiação térmica, quando comparado a um corpo negro, que tem emissividade igual a 1 (ou seja, tudo que ele recebe ele transmite)

\section{MATERIAIS E METODOS}

\subsection{Instrumentação}

Nas Figuras 4 e 5 tem-se os instrumentos utilizados, ou seja, um termo higrômetro digital Modelo MTH-1362 e uma câmera termográfica Modelo Flir T200, Figuras 4 e 5, respectivamente.

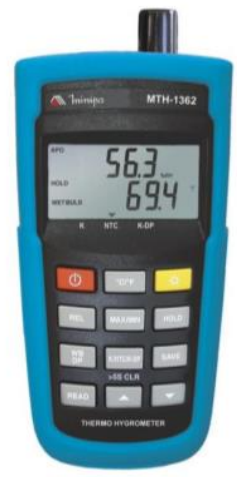

Figura 4. Termo higrômetro digital. Fonte: Autor (2019).

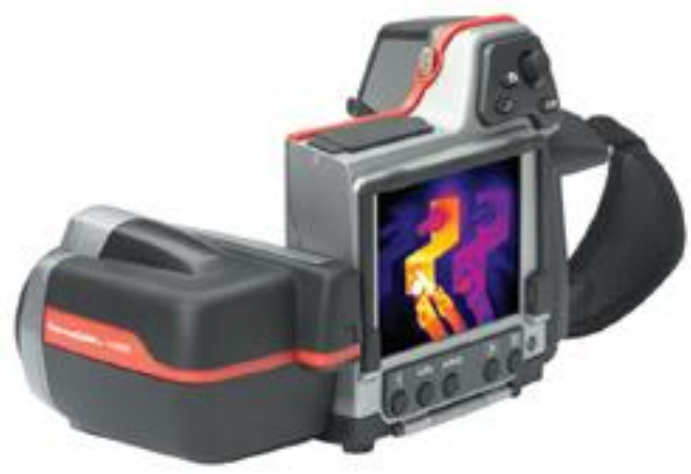

Figura 5. Câmera termográfica. Fonte: Autor (2019).

As tabelas a seguir mostram as especificações dos instrumentos utilizados: 


\begin{tabular}{|l|l|}
\hline Faixa de temperatura & $-20^{\circ} \mathrm{C}$ a $350^{\circ} \mathrm{C}$ \\
\hline Frame Rate & $9 \mathrm{~Hz}$ \\
\hline Campo de visão / distância mínima do foco & $25^{\circ} \times 19^{\circ} / 0,4 \mathrm{~m}$ \\
\hline Sensibilidade térmica & $0,08^{\circ} \mathrm{C} \mathrm{a} 30^{\circ} \mathrm{C}$ \\
\hline Tipo de detector - Microlímetro de mesa focal & $240 \times 180$ pixels \\
\hline Faixa espectral & 7,5 a $13 \mu \mathrm{m}$ \\
\hline Lente & $\begin{array}{l}25^{\circ}\left(\text { opcionais } 6^{\circ}, 15^{\circ}, 45^{\circ}, 90^{\circ}, \text { lentes de }\right. \\
100,50 \text { e } 25 \mu \mathrm{m} \text { disponíveis })\end{array}$ \\
\hline Modos de medição & $\begin{array}{l}5 \text { medidores do ponto, } 5 \text { áreas da caixa, } \\
\text { isoterma, auto ponto quente / frio, Delta T }\end{array}$ \\
\hline Correção de medição & $\begin{array}{l}\text { Temperatura ambiente refletida e correção de } \\
\text { emissividade }\end{array}$ \\
\hline
\end{tabular}

Tabela 1. Especificações da câmera termográfica modelo FLIR T200

\begin{tabular}{|l|l|}
\hline Faixas de Temperatura & $\begin{array}{l}\mathrm{T} 1: 0^{\circ} \mathrm{C} \text { a } 60^{\circ} \mathrm{C} ; \\
\text { T2: }-50^{\circ} \mathrm{C} \text { a } 1000^{\circ} \mathrm{C}\end{array}$ \\
\hline Tempo de resposta para umidade & 60 segundos \\
\hline Taxa de amostragem & 1 vez/s \\
\hline Coeficiente de Temperatura & $0.1 \mathrm{x}$ (precisão especificada) $/{ }^{\circ} \mathrm{C}\left(<18^{\circ} \mathrm{C}\right.$ ou $>$ \\
& $\left.28^{\circ} \mathrm{C}\right)$ \\
\hline Ambiente de Operação & $0^{\circ} \mathrm{C} \sim 50^{\circ} \mathrm{C}, \mathrm{RH}<80 \%$ \\
\hline Precisão (temperatura) & $\mathrm{T} 1: 0^{\circ} \mathrm{C} \sim+10^{\circ} \mathrm{C} \pm 2^{\circ} \mathrm{C} ;+10^{\circ} \mathrm{C} \sim+45^{\circ} \mathrm{C} \pm$ \\
& $0.5^{\circ} \mathrm{C} ;+45^{\circ} \mathrm{C} \sim+60^{\circ} \mathrm{C} \pm 2^{\circ} \mathrm{C} ;$ \\
& $\mathrm{T} 2:-50^{\circ} \mathrm{C} \sim+1000^{\circ} \mathrm{C} \pm\left(0.1 \%+1^{\circ} \mathrm{C}\right) ;$ \\
\hline Altitude & Até 2000 metros \\
\hline Umidade relativa & $0 \sim 100 \% \mathrm{RH}$ \\
\hline Precisão (umidade) & $\pm 2.5 \% \mathrm{RH}$ em $25^{\circ} \mathrm{C} \mathrm{para} 10 \% \sim 90 \% \mathrm{RH} ;$ \\
& $\pm 5 \%$ em $25^{\circ} \mathrm{C}$ para $0 \sim 10 \% \mathrm{RH}, 90 \% \sim 100 \%$ \\
\hline
\end{tabular}

Tabela 2. Especificações do termo higrômetro digital Modelo MTH-1362

\subsection{Procedimentos da Inspeção}

Com base na revisão bibliográfica e experiência do coordenador da equipe que participou dessa inspeção, foram utilizados diferentes parâmetros para parametrizar a câmera termográfica.

Através do higrômetro digital encontrou-se valores da temperatura ambiente, temperatura da parede e umidade relativa do ar. Como a inspeção foi realizada em dias diferentes, e algumas salas tem maior ventilação e iluminação solar, cada sala possui uma temperatura de referência e também uma umidade relativa. A emissividade é mantida constante devido o material a ser analisado não foi alterado, assim para concreto $\boldsymbol{\varepsilon}=\mathbf{0 , 9 7}$. 


\section{ANÁLISE DOS RESULTADOS}

A frente de prédio possui maior insolação e ventilação. Através da inspeção visual, não foram encontrados focos de umidade ou infiltração, o que foi confirmado através da Inspeção Termográfica.

Já as salas ao fundo do prédio apresentam focos de umidade e infiltrações. Também foi possível perceber um forte cheiro de mofo. Na Figuras 6 tem-se o registro da existência de infiltrações. Na parte de trás do prédio há uma distância relativamente pequena entre o antigo prédio do DEMEC e DCTEF a os fundos da residência que faz divisa com o referido prédio.
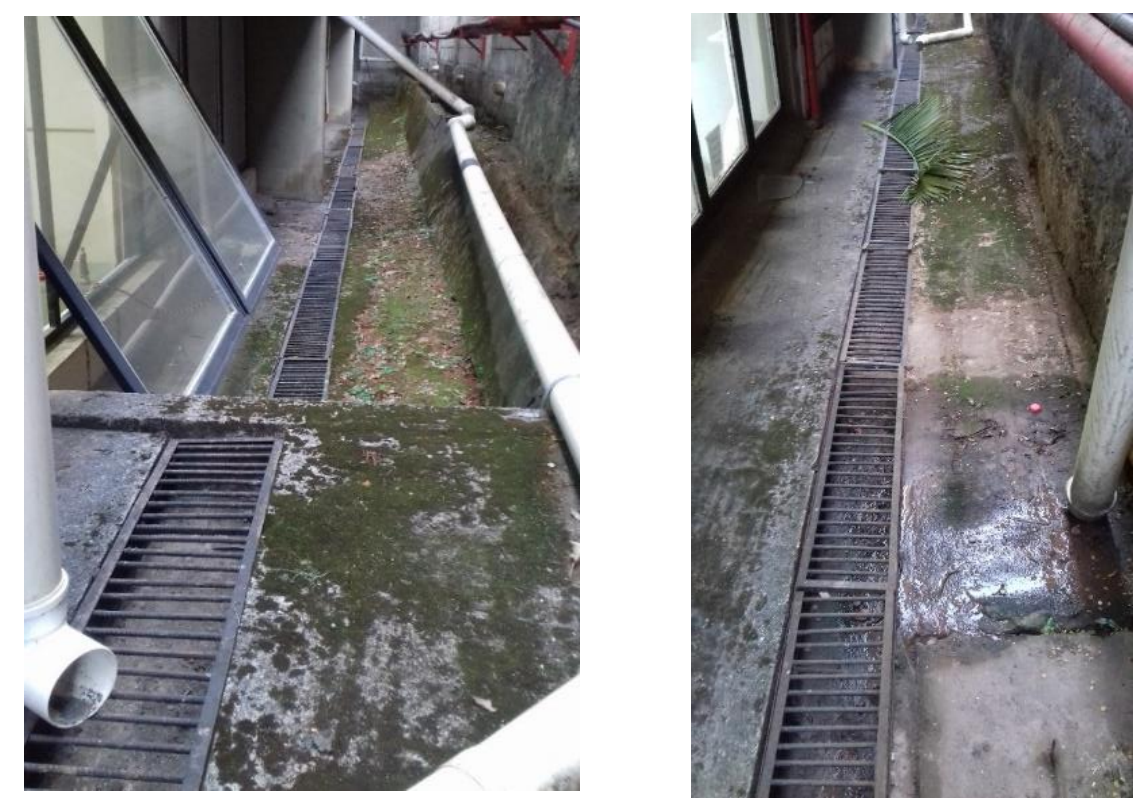

Figura 6. Parte de trás do prédio DEMEC e DCTEF. Fonte: Autor (2019).

Como há pouco incidência da luz do sol, essa área geralmente é mais úmida, conforme podese perceber através dos termogramas, Figura 7. Essa umidade se intensifica quando chove gerando grande acúmulo de água da canalização favorecendo infiltrações nas salas uma vez que a umidade se infiltra através do solo. Esse fato também é intensificado pelo fato de as salas do prédio estarem em um nível mais baixo que a canalização da água da chuva. 

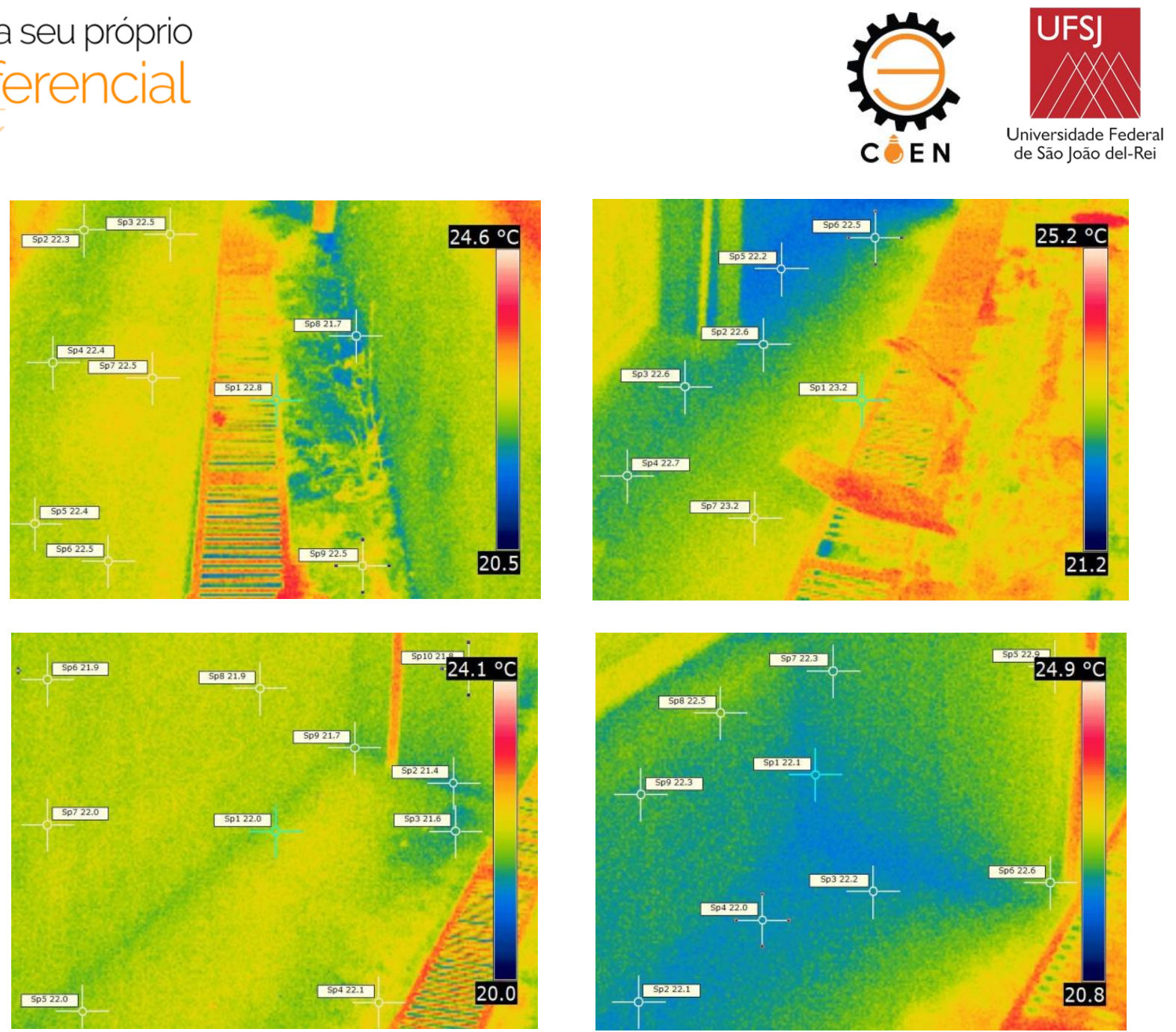

Figura 7. Termograma | Parte de trás do prédio DEMEC e DCTEF. Fonte: Autor (2019).

Na Figura 8, lado esquerdo, tem-se a planta baixa do antigo prédio do DEMEC e DCTEF. No lado direito tem-se o destaque da planta baixa das Sala 1.07 identificando onde foram realizados os termogramas, Figura 9.
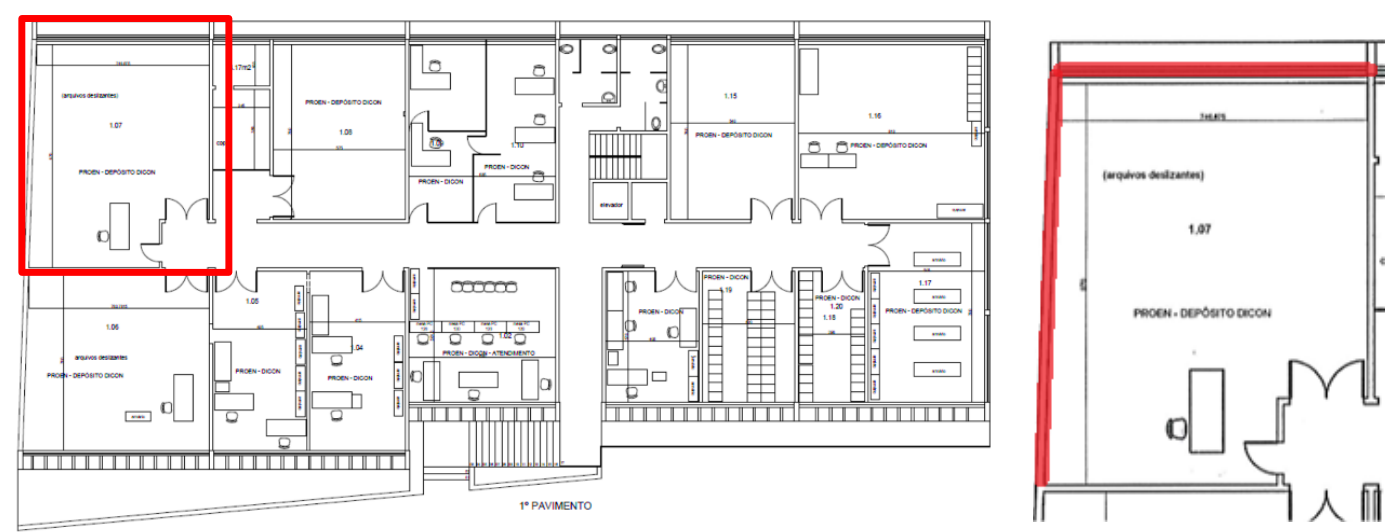

Figura 8. Destaque da planta baixa da Sala 1.07. Fonte: Autor (2019). 

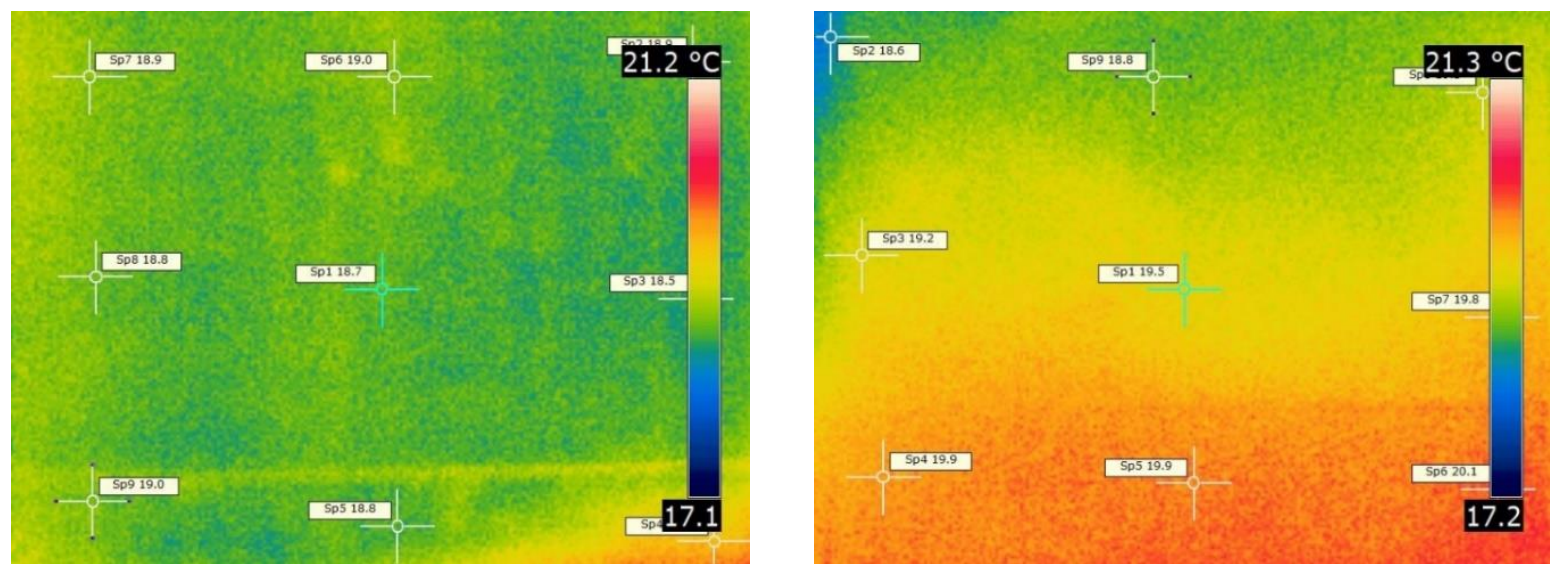

Figura 9. Termogramas da Sala 1.07. Fonte: Autor (2019).

Para a análise dos termogramas da Sala 1.07 é preciso levar em consideração a chuva que ocorreu alguns dias antes da inspeção, o que interferiu no termograma dessa sala, em particular, mas, devido ao forte odor de mofo e o desgaste visível nas paredes, é possível confirmar as infiltrações se comparada com as demais salas do prédio.

$\mathrm{Na}$ Figura 10, lado esquerdo, tem-se a planta baixa do antigo prédio do DEMEC e DCTEF. No lado direito tem-se o destaque da planta baixa das Sala 1.08 identificando onde foram realizados os termogramas, Figura 11.
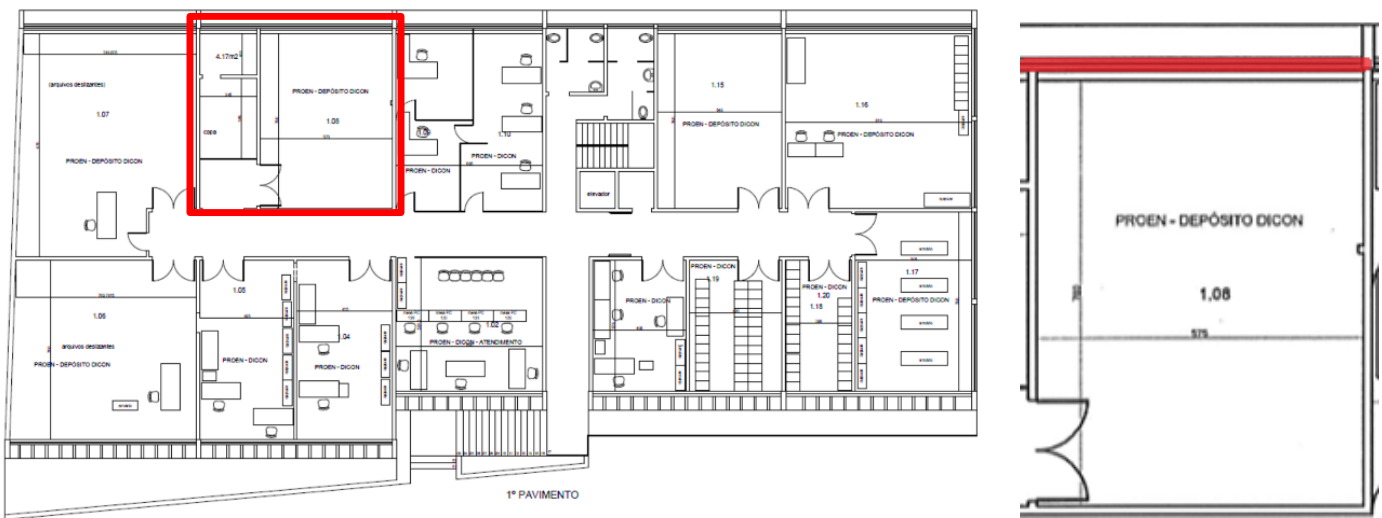

Figura 10. Destaque da planta baixa da Sala 1.08. Fonte: Autor (2019). 

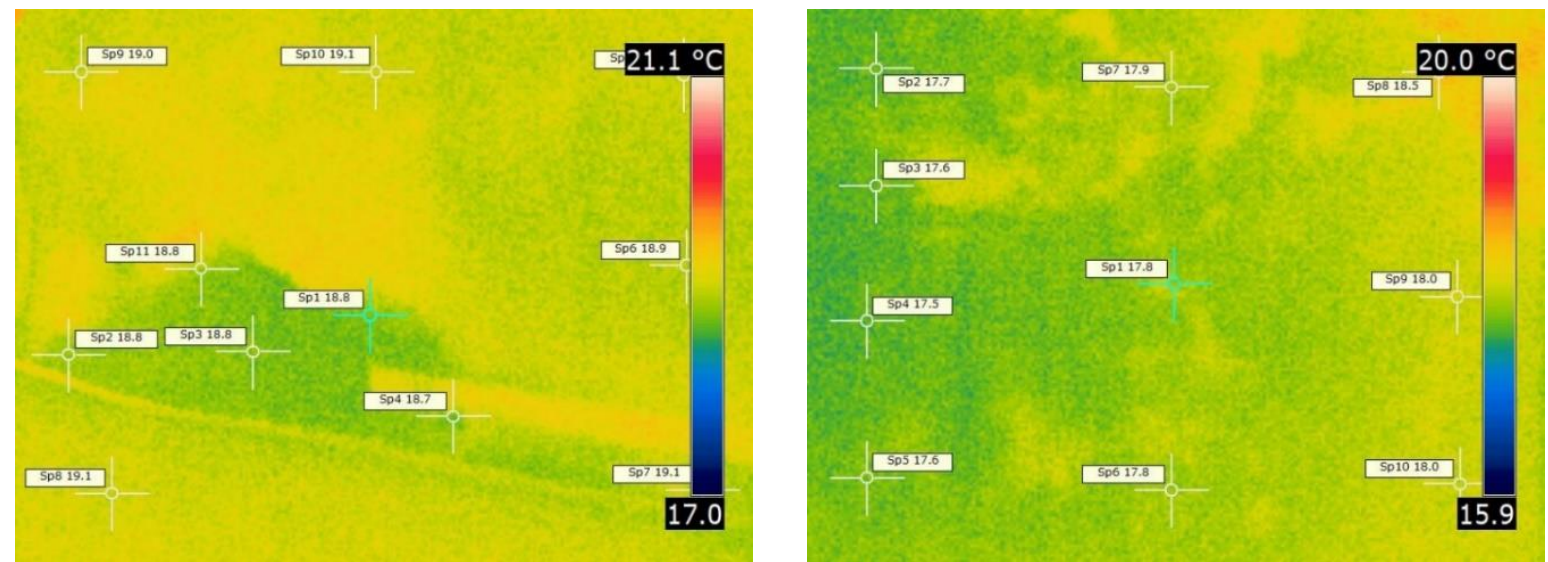

Figura 11. Termogramas da Sala 1.08. Fonte: Autor (2019).

Na Figura 12, lado esquerdo, tem-se a planta baixa do antigo prédio do DEMEC e DCTEF. No lado direito tem-se o destaque da planta baixa das Salas 1.09 e 1.10 identificando onde foram realizados os termogramas, Figura 13.
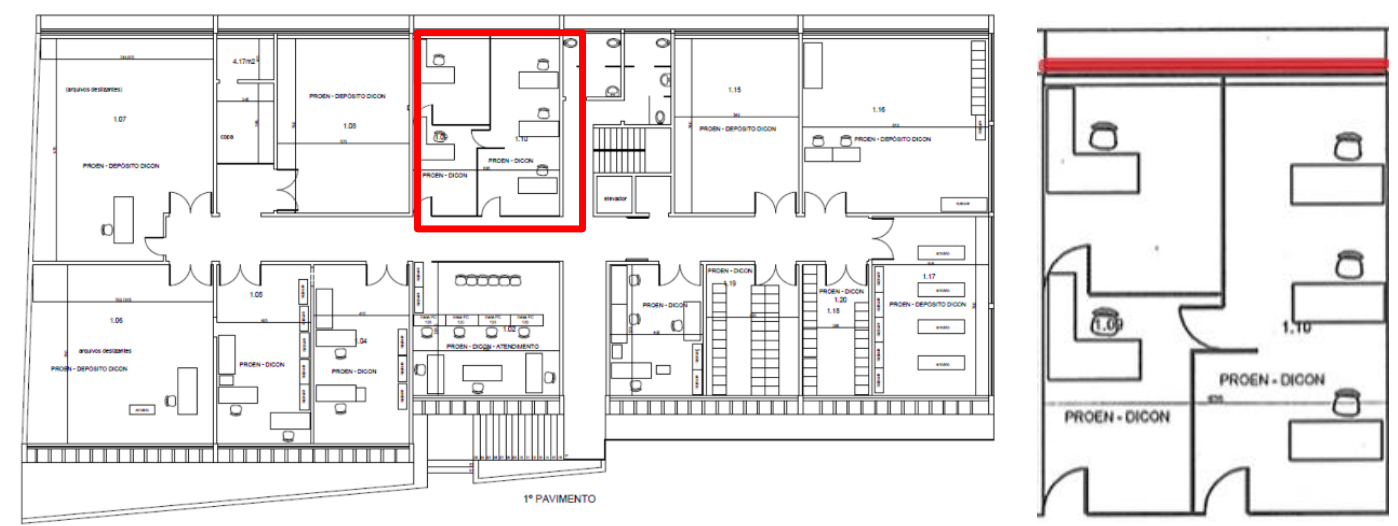

Figura 12. Destaque da planta baixa das Salas 1.09 e 1.10. Fonte: Autor (2019).

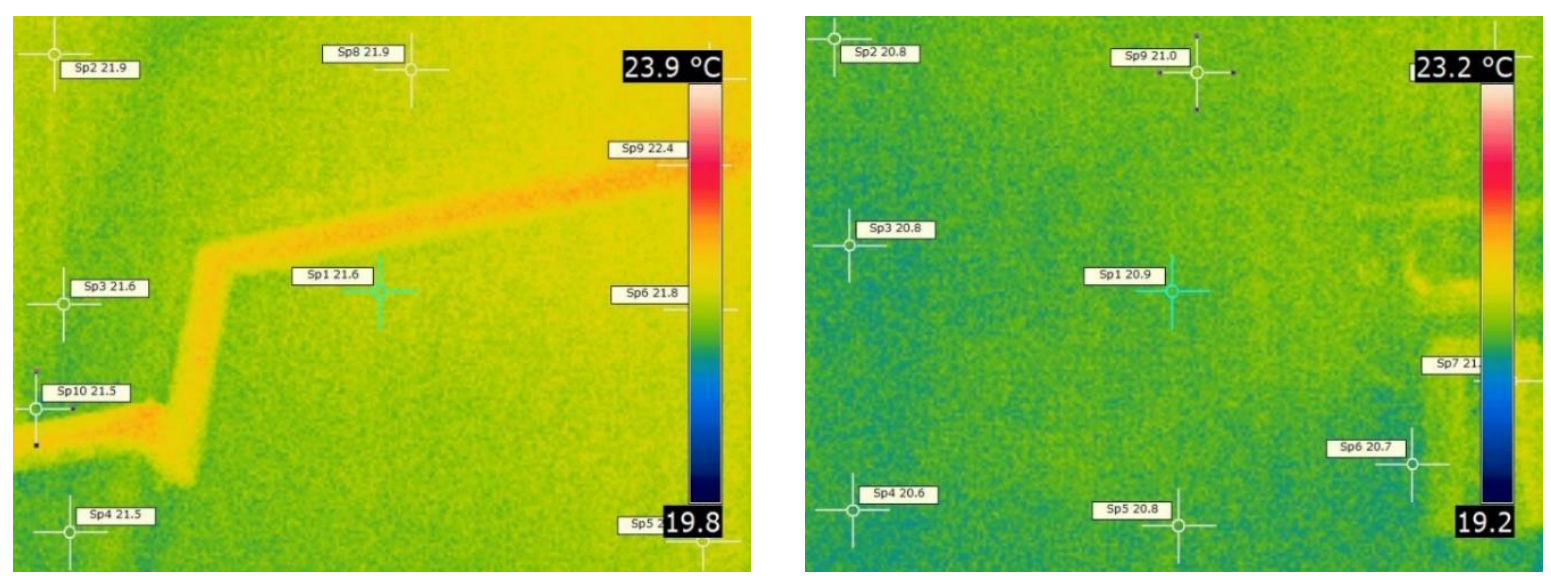

Figura 13. Termogramas das Salas 1.09 e 1.10. Fonte: Autor (2019). 
Na Figura 14, lado esquerdo, tem-se a planta baixa do antigo prédio do DEMEC e DCTEF. No lado direito tem-se o destaque da planta baixa da Sala 1.15 identificando onde foram realizados os termogramas, Figura 15.


Figura 14. Destaque da planta baixa da Sala1.15. Fonte: Autor (2019).

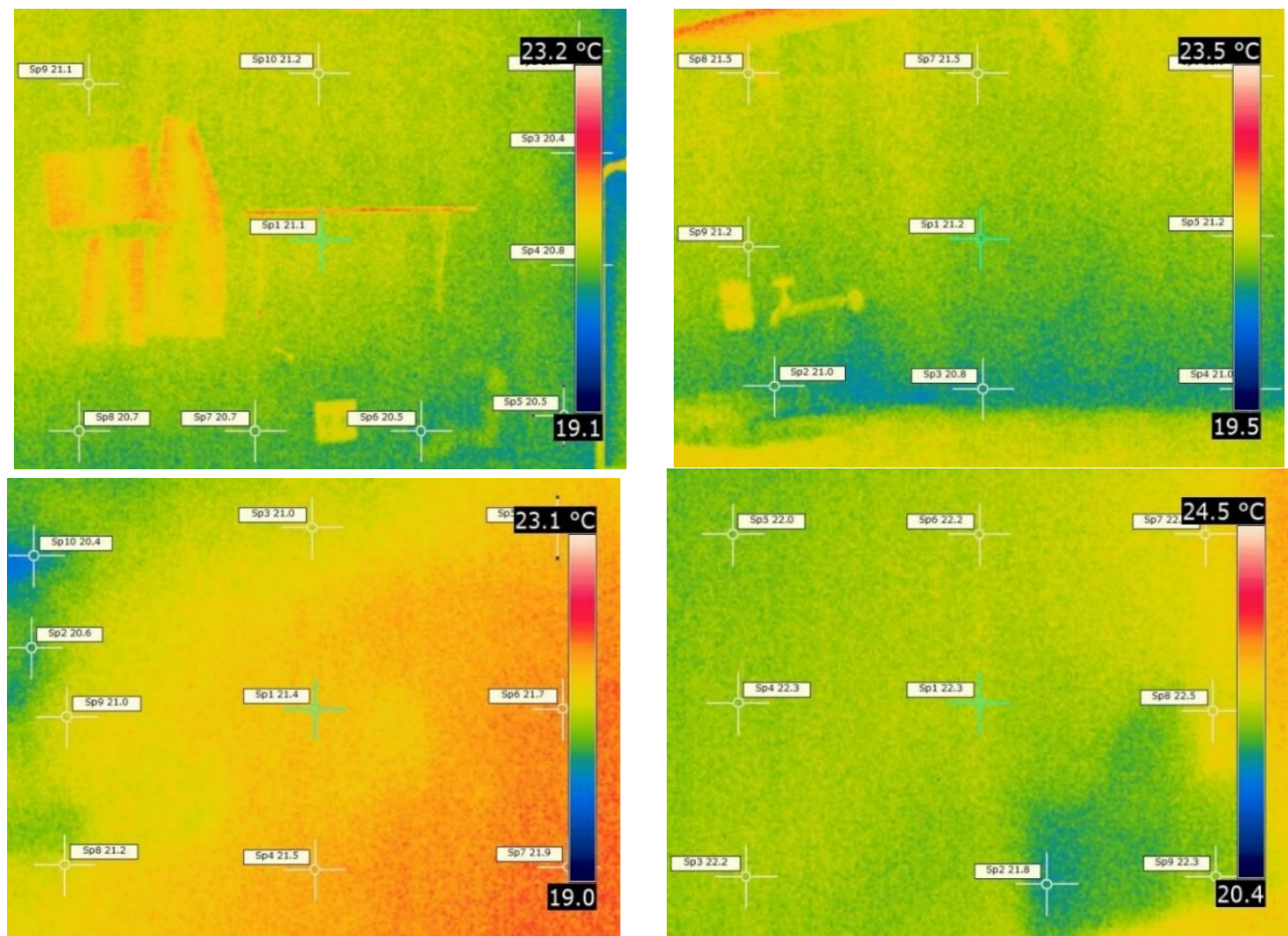

Figura 15. Termogramas da Sala1.15. Fonte: Autor (2019).

Na Figura 16, lado esquerdo, tem-se a planta baixa do antigo prédio do DEMEC e DCTEF. No lado direito tem-se o destaque da planta baixa da Sala 1.16 identificando onde foram realizados os termogramas, Figura 17. 

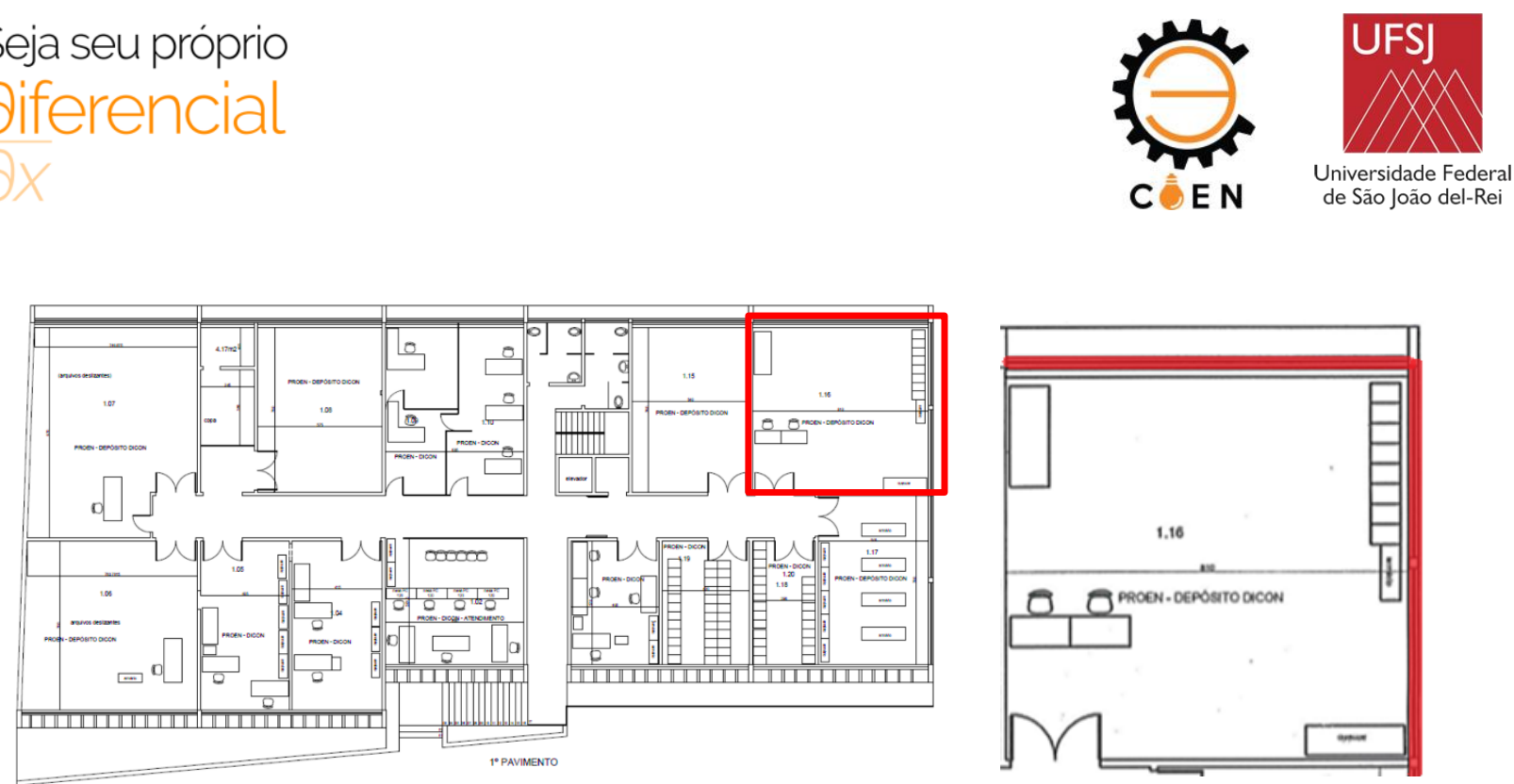

Figura 16. Destaque da planta baixa da Sala1.16. Fonte: Autor (2019).
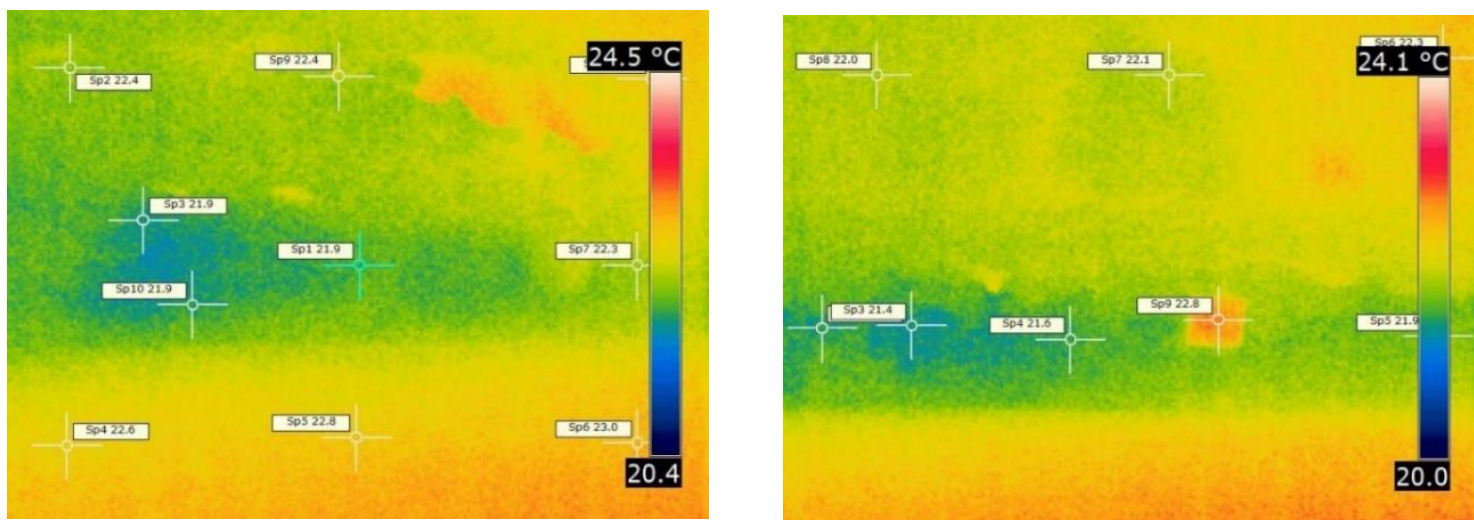

Figura 17. Termogramas da Sala1.16. Fonte: Autor (2019).

Na Figura 18, lado esquerdo, tem-se a planta baixa do antigo prédio do DEMEC e DCTEF. No lado direito tem-se o destaque da planta baixa da Sala 1.17 identificando onde foram realizados os termogramas, Figura 19.
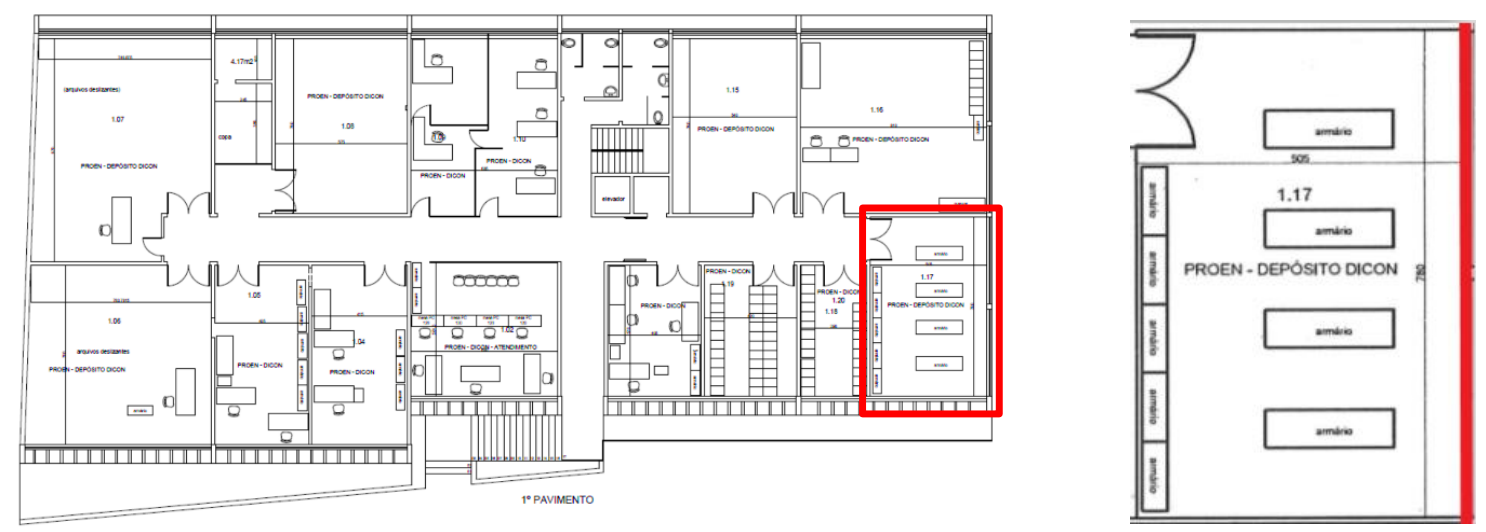

Figura 18. Destaque da planta baixa da Sala1.17. Fonte: Autor (2019). 

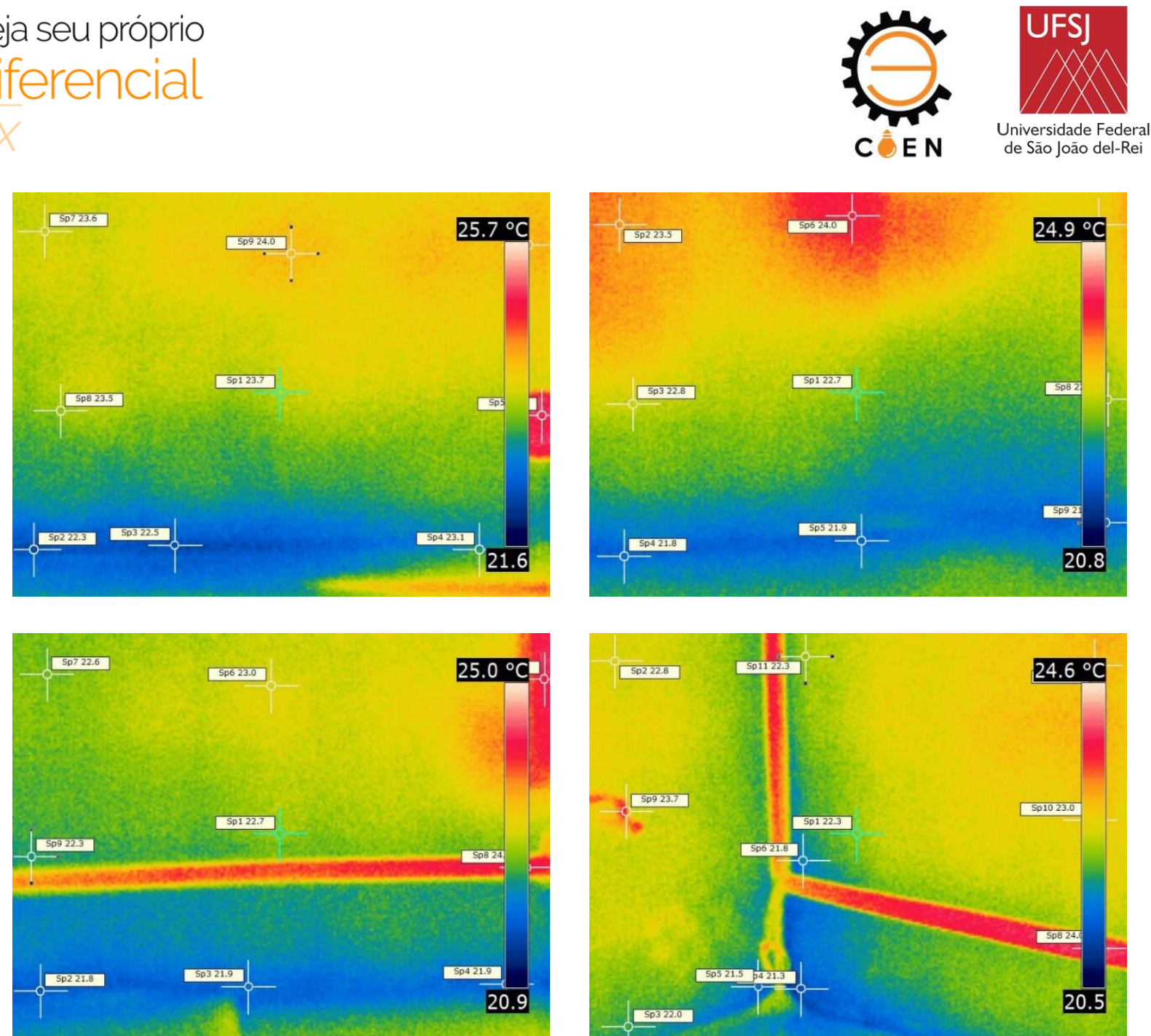

Figura 19. Termogramas da Sala1.17. Fonte: Autor (2019).

\section{CONCLUSÃO E SUGESTÕES}

Os danos causados pela infiltração são visivelmente perceptíveis na maioria das salas. Através da Termografia Infravermelha foi possível confirmar as infiltrações e focos de umidade e ainda observar os diferentes níveis dos danos causados em cada região.

É na parte de trás do antigo prédio do DMEC e DCTEF onde os problemas mais graves estão presentes. A umidade relativa do ar, medida com termo higrômetro, nesta região é sempre maior que a umidade nas laterais e na frente do prédio devido à falta de ventilação e insolação. Consequentemente, os termogramas apresentam temperatura menor em relação à outras áreas do prédio.

De acordo com Neto (2017), a estratégia de recuperação que poderia ser adotada seria a aplicação de uma solução de água sanitária e água (1:1 para cada), com uma escova de cerdas médias embebidas da solução é necessário esfregar a mancha de mofo ou bolor. Para os lugares de difícil acesso, é possível colocar a solução em um borrifador pequeno e aplicar diretamente no mofo ou bolor, pulverizando-o. Em seguida, esfregar normalmente com uma escova. A água sanitária é muito eficaz para matar fungos e esporos de mofo. O ingrediente ativo nela, o hipoclorito de sódio, também é o ingrediente principal de muitos produtos de remoção de mofo. Posteriormente passar apenas água limpa e deixar secar. 
Para a existência de bolhas, a estratégia proposta consiste em realizar à raspagem da região deteriorada com uma espátula de aço, após realizar o lixamento do local afetado para nivelar o local a ser recuperada e após comum pano úmido retirar a poeira e esperar secar. Em seguida, é preparada a massa acrílica e com uma desempenadeira são corrigidas as imperfeições que ficaram na parede, esperando a secagem de acordo com o tempo indicado pelo fornecedor do produto de massa acrílica. Após esse procedimento novamente é necessário lixar para corrigir as últimas imperfeições como ondulações da massa acrílica, é necessária a retirada do pó e de resíduos novamente com um pano úmido e após é necessário à aplicação de uma seladora conforme indicação do fornecedor, realizar a pintura do local novamente de acordo coma cor desejado.

E a pintura deve ser realizada com uma tinta anti-mofo ou tinta acrílica elastomérica que repele imediatamente a água, oferecendo proteção contra umidade e ações do tempo.

\section{DIREITOS AUTORAIS.}

Os autores são os únicos responsáveis pelo conteúdo das informações contidas neste artigo.

\section{REFERÊNCIAS}

CORTIZO, E. C. Avaliação Da Técnica de Termografia Infravermelha Para Identificação de Estruturas Ocultas e Diagnóstico De Anomalias Em Edificações. Ênfase em Edificações do Patrimônio Histórico. Tese de Doutorado em Engenharia Mecânica- Universidade Federal de Minas Gerais (UFMG). Belo Horizonte, 2007.

GALlO, E. A., RIBEIRO, F. N., Índice de Conforto Térmico ISO7730 em Automação Predial. Trabalho De Graduação Em Engenharia De Controle E Automação, Publicação FT.TG-no ${ }^{\circ}$, Faculdade de Tecnologia, Universidade de Brasília, Brasília, DF, 98p. (2007).

INCROPERA, F. P., DE WITT. Fundamentos de Transferência de Calor e de Massa. 6.ed. Rio de Janeiro: Livros Técnicos e Científicos, 2008.

LA FÉ, E. P. Critérios e padrões de comportamento para avaliação de descolamentos cerâmicos com termografia de infravermelho. Tese de Doutorado em Engenharia Civil- Universidade de Brasília. 2017.

NETO, Alcides Proinelli. Manifestações Patológicas De Umidade Nas Paredes: Um estudo de caso na região sul de Santa Catarina. Trabalho de Conclusão de Curso- Universidade do Sul de Santa Catarina, 2017.

OLIVEIRA, D. B. Manutenção preditiva; Termografia; Indústria sucroalcooleira; Manutenção preditiva; Termografia; Indústria sucroalcooleira. Trabalho de Conclusão de Curso apresentado ao Centro Universitário de Formiga - UNIFOR-MG, 2012

PEDRA, S. A. Potencialidades da termografia infravermelha aplicada ao design do conforto térmico de alvenaria estrutural. Dissertação de Mestrado em Design- Universidade do Estado de Minas Gerais, UEMG. 2011.

SILVA, F. A. M. Diagnóstico da Envolvente de um Edifício Escolar com Recurso a Análise Termográfica. Dissertação de Mestrado em Engenharia Civil e do Ambiente- Escola Superior de Tecnológica e Gestão. 2016.

SOUZA, V. C. Organização e gerenciamento da manutenção: programação e controle de manutenção. - 4a . Ed. - São Pauso: All Printe Editora. 2011. 
Portal do Governo do Estado. Como conservar seus documentos. Disponível em: http://www.saopaulo.sp.gov.br/spnoticias/ultimas-noticias/sabe-como-conservar-seus-documentoso-arquivo-publico-te-ensina/ Acessado em 13 de julho de 2019.

Tecno Ferramentas. Termo Higrômetro digital MTH-1362. Disponível em: https://www.tecnoferramentas.com.br/termo_higrometro-ponto-orvalho-minipa-mth_1362/p/ Acessado em 18 de agosto de 2019.

\section{THERMOGRAPHIC INSPECTION IN THE ANCIENT DCTEF-UFSJ BUILDING}

ABSTRACT: Thermography is a non-destructive predictive maintenance technique, where it is possible to monitor the temperature and thermograms of the desired region of study. The analysis of temperature variation is very important for understanding and detecting both electrical and mechanical faults. This technique is also used in civil construction, in the detection of leaks, drafts and fissures. A thermographic inspection was carried out in the old building DCTEF-UFSJ, with the help of a thermographic camera (model FLIR T200) and a digital hygrometer, based on previous studies, there are parameters for the camera configuration, such as ambient temperature, temperature of the wall and the relative humidity of the air, obtained by the digital hygrometer in addition to the emissivity of the concrete $\varepsilon=0.97$, the latter parameter being kept constant due to all the analyzed walls being made of this material. This analysis was performed in order to identify possible infiltrations and accumulations of humidity to verify if the conditions of the building are adequate for the change of the DICON and the storage of files. From the images obtained by the inspection, it was observed that the front of the building, which has greater solar insolation and ventilation did not present great problems of infiltration, in contrast the rooms at the bottom of the building have a greater focus of humidity and infiltration, besides a strong musty smeel.

KEYWORDS: Predictive Maintenance, Infrared Thermography, Civil Construction. 